University of Nebraska - Lincoln

DigitalCommons@University of Nebraska - Lincoln

USDA National Wildlife Research Center - Staff Publications
U.S. Department of Agriculture: Animal and Plant Health Inspection Service

2018

Intercanine width measurements to aid predation investigations: a comparison between sympatric native and non-native carnivores in the Mexican wolf recovery area

\author{
Tana Verzuh \\ USDA APHIS Wildlife Services NWRC \\ David L. Bergman \\ USDA APHIS Wildlife Services \\ Scott C. Bender \\ Navajo Nation Veterinary Program \\ Maggie Dwire \\ NMESFO \\ Stewart W. Breck \\ USDA/APHIS/WS National Wildlife Research Center, stewart.w.breck@aphis.usda.gov \\ Follow this and additional works at: https://digitalcommons.unl.edu/icwdm_usdanwrc \\ Part of the Life Sciences Commons
}

Verzuh, Tana; Bergman, David L.; Bender, Scott C.; Dwire, Maggie; and Breck, Stewart W., "Intercanine width measurements to aid predation investigations: a comparison between sympatric native and nonnative carnivores in the Mexican wolf recovery area" (2018). USDA National Wildlife Research CenterStaff Publications. 2209.

https://digitalcommons.unl.edu/icwdm_usdanwrc/2209

This Article is brought to you for free and open access by the U.S. Department of Agriculture: Animal and Plant Health Inspection Service at DigitalCommons@University of Nebraska - Lincoln. It has been accepted for inclusion in USDA National Wildlife Research Center - Staff Publications by an authorized administrator of DigitalCommons@University of Nebraska - Lincoln. 


\title{
Intercanine width measurements to aid predation investigations: a comparison between sympatric native and non-native carnivores in the Mexican wolf recovery area
}

\author{
Tana Verzuh, David L. Bergman, Scott C. Bender, ${ }^{\circledR}$ Maggie Dwire, and Stewart W. Breck* \\ USDA APHIS Wildlife Services, National Wildlife Research Center, 4101 LaPorte Avenue, Fort Collins, CO 80521, USA \\ $(T V, S W B)$ \\ USDA APHIS Wildlife Services, 8836 N 23 Avenue, Suite 2, Phoenix, AZ 85021, USA (DLB) \\ Navajo Nation Veterinary Program, Navajo Nation, Chinle, AZ 86503, USA (SCB) \\ U.S. Fish and Wildlife Service, New Mexico Ecological Services Field Office (NMESFO), 2105 Osuna Road NE, Albuquerque, \\ NM 87113, USA (MD) \\ *Correspondent: Stewart.W.Breck@aphis.usda.gov
}

\begin{abstract}
Mexican wolves (Canis lupus baileyi) share their range with a number of sympatric carnivores, many of which are a concern to livestock producers because they can prey on livestock. Determining which predator species is responsible for killing livestock is important for determining appropriate management actions and for the conservation of Mexican wolves. A variety of information can be used to decipher which carnivore species was responsible for making a kill, and mandibular (upper) and maxillary (lower) intercanine width measurements (i.e., bite mark analysis) can aid this process. No research has been conducted to validate the usefulness of bite mark analysis; thus, we used dentition measurements from Mexican wolves, coyotes (Canis latrans), feral dogs (Canis familiaris), bobcats (Lynx rufus), mountain lions (Puma concolor), and gray foxes (Urocyon cinereoargenteus) and an overlap coefficient to evaluate the degree of overlap in intercanine width between these species. We found that larger carnivore species had greater overlap than smaller carnivores, feral dogs overlapped widely with all the medium-to-large carnivores, and upper and lower intercanine width measurements provided similar information. Our data indicated that when investigating livestock depredations for Mexican wolves, bite mark analyses should be evaluated along with additional forensic evidence due to the overlap between many of the carnivore species, and that measurements between 28 and $35 \mathrm{~mm}$ have the greatest uncertainty because this range overlaps with feral dogs, mountain lions, and coyotes.
\end{abstract}

Key words: coyotes, depredation, feral dogs, intercanine width, Mexican wolves, mountain lions, predation

Mexican wolves (Canis lupus baileyi) are a critically endangered subpopulation of wolves in the southwestern United States and Mexico, with a current minimum population of 114 individuals in the United States (U.S. Fish and Wildlife Service Press Release 2018). Mexican wolves preying on livestock are a major concern for wildlife managers responsible for their recovery and livestock producers attempting to live with wolves in the recovery area (Breck et al. 2011; Amirkhiz et al. 2018). For example, in 2016, the Mexican Wolf Interagency Field Team and several nongovernmental organizations spent $\$ 128,375$ and $12,640 \mathrm{~h}$ implementing proactive management strategies to reduce issues between Mexican wolves and cattle (U.S. Fish and Wildlife Service 2017). Furthermore, in
Arizona, livestock owners experiencing depredations by Mexican wolves have the potential to receive compensation for losses, and importantly, the pay-out for livestock depredation depends upon correct identification of the species making kills on livestock (Arizona Game and Fish Livestock Board; U.S. Fish and Wildlife Service, Mexican Wolf Depredation Compensation 2016).

An array of methods is used to help identify which predator caused a predation event. Officials can examine the kill site around the carcass looking for tracks, hair, wool, blood pools, and feces; collect salivary, hair, or scat samples for genetic testing (Blejwas et al. 2006; Onorato et al. 2006; Caniglia et al. 2013; Mumma et al. 2013); and search for rake marks,

Published by Oxford University Press on behalf of American Society of Mammalogists 2018.

This work is written by (a) US Government employee(s) and is in the public domain in the US. 
hemorrhaging, and puncture wounds caused by the maxillary and mandibular canines on the carcass (Acorn and Dorrance 1990; Clucas 2005; New Mexico Cooperative Extension Service and Range Improvement Task Force 2008; Foust 2010). Often, it is straightforward distinguishing between kills made by felids, ursids, and canids because of the way each of these predators makes kills and subsequently leaves evidence (Clucas 2005; New Mexico Cooperative Extension Service and Range Improvement Task Force 2008). However, it can be difficult distinguishing between species within a genus; this is especially so between gray wolves (Canis lupus), feral dogs (Canis familiaris), and coyotes (Canis latrans-Ciucci and Boitani 1998; Foust 2010). Other times, very little evidence exists at a kill site except for predator bite marks left on the remaining hide and bones (Murman et al. 2006). In these cases, bite mark analysis, usually intercanine width measurements, can be an important piece of information to aid in the investigative process (Lyver 2000; Murman et al. 2006; Bergman et al. 2010; Foust 2010; Young et al. 2015).

A major limitation to bite mark analysis is a poor understanding of the range in intercanine width for carnivore species that can help guide predation investigations. Only a few studies have examined intercanine width of several carnivore species (Murman et al. 2006; Foust 2010); however, we could find nothing published on Mexican wolves, or focused explicitly on comparing the overlap of intercanine width between species. Predation by feral dogs is a worldwide problem (e.g., Echegaray and Vilà 2010) and sometimes is misidentified as wolf predation (Caniglia et al. 2013; Duarte et al. 2016). Feral dogs are common throughout Arizona and thus are an important consideration when investigating predation incidents. Furthermore, Mexican wolves are smaller than gray wolves and coexist with coyotes; thus, the potential to confuse coyote predation as predation by Mexican wolves is potentially greater than in other populations of wolves with larger body sizes.

Our primary goal was to aid predation investigations by gathering data on mandibular and maxillary intercanine widths of Mexican wolves and sympatric carnivores (i.e., gray foxes [Urocyon cinereoargenteus], bobcats [Lynx rufus], coyotes, feral dogs, and mountain lions [Puma concolor]) that can aid analyses of bite marks. We used a novel method of comparing intercanine width measurements (i.e., determining probability density functions from width measurements and then calculating an overlap coefficient between carnivore species) in an effort to identify measurements that were critical for investigations of bite marks involving Mexican wolves. This method allowed us to identify measurements of intercanine width that had the most potential to be multiple species and therefore the least reliable measurements for analysis of bite marks.

\section{Materials And Methods}

The study took place across the state of Arizona. The Mexican wolf experimental recovery area in Arizona covers the lower half of the state from east to west from I-40 south to the border with Mexico (U.S. Fish and Wildlife Service 2017). From 2009 to 2014, we measured upper and lower intercanine width opportunistically on gray foxes, bobcats, coyotes, and mountain lions that were removed for purposes of protection of agriculture or human health and safety. Intercanine width measurements of feral dogs were conducted from 2008 to 2013 after feral dog roundups by the Navajo Nation Animal Control Program or in conjunction with wildlife damage management activities. Measurements of Mexican wolves were taken from existing records maintained of animals managed under the U.S. Fish and Wildlife Service Mexican Wolf Species Survival Plan (U.S. Fish and Wildlife Service 2009). Only adults were included in our analyses because adults are the primary individuals making kills. Animals with missing or broken teeth were not measured.

Intercanine width was measured using "point-to-point" measurements with digital calipers with individual jaws of the calipers placed on the center of each maxillary or mandibular tip (Murman et al. 2006) and measured to the other maxillary or mandibular tip. Distance was measured in millimeters within 1 decimal place. For individuals with worn teeth, the individual taking the measurement estimated the approximate center point on the canine cusp and placed a single jaw of the calipers at that location. Multiple observers recorded measurements and there is the potential for interobserver biases, but it is likely this error was minimal because all observers attended several hours of training before recording measurements. Furthermore, even if interobserver error did occur, it is unlikely that it impacted our objectives of comparing overlap between species because all observers attained measurements on multiple species, thus minimizing impact on the between-species comparisons.

We measured a total of 1,757 adult animals: 39 gray foxes, 24 bobcats, 1,407 coyotes, 197 feral dogs, 63 Mexican wolves, and 27 mountain lions (Table 1). We attained upper intercanine widths from all individuals but could not attain lower intercanine width measurements from 17 animals (2 gray foxes, 10 coyotes, 3 feral dogs, and 2 Mexican wolves). To determine the amount of overlap in intercanine width between species, we calculated the degree of overlap (i.e., overlap coefficient) for all pairs of native species whose median values were $10 \mathrm{~mm}$ or less apart, and between feral dogs and all native carnivores. Following Lyver (2000), when calculating the overlap coefficients between species, we combined data from both sexes because determining the sex of a predator during a field investigation is essentially impossible. We calculated overlap coefficients separately for upper and lower intercanine widths, and also combined the upper and lower intercanine widths into a single value, to understand how much separate versus combined measurements would influence overlap coefficients between species. We used program R (R Core Team 2015) and the package "overlap" (Ridout and Linkie 2009) to calculate the overlap coefficient. This package was developed for comparing time series data and requires data in radians; thus, we converted our data to radians by using the $\mathrm{R}$ package "scales" and the function "rescale" to convert intercanine width measurements to vary between 0 and $2 \pi$. We then calculated the kernel densities for each data set using the "density" function and the degree of overlap between these kernel densities using the "overlapTrue" 
Table 1.-Upper and lower intercanine width data for adult male and female gray foxes (Urocyon cinereoargenteus), bobcats (Lynx rufus), coyotes (Canis latrans), feral dogs (Canis familiaris), Mexican wolves (Canis lupus baileyi), and mountain lions (Puma concolor) collected in Arizona, United States. Sample sizes, mean, range, and SDs are presented. All measurements are in mm. Weight ranges are not from data we collected but instead are values reported by Feldhamer et al. (2003) and Nowak (2005) ${ }^{2}$. We included the full range of body masses and intercanine measurements for dogs mostly for reference, and because even the smaller feral dogs might scavenge if given the opportunity, although are unlikely to depredate livestock.

\begin{tabular}{|c|c|c|c|c|c|c|c|}
\hline \multirow[t]{2}{*}{ Species } & \multirow[t]{2}{*}{ Weight range (kg) } & \multicolumn{3}{|c|}{ Upper intercanine width } & \multicolumn{3}{|c|}{ Lower intercanine width } \\
\hline & & $n$ & Range & $\bar{X} \pm S D$ & $n$ & Range & $\bar{X} \pm S D$ \\
\hline Gray fox (male) & $3.0-7.0^{1}$ & 18 & $14.2-19.5$ & $17.5 \pm 1.4$ & 17 & $13.5-17.3$ & $15.9 \pm 1.1$ \\
\hline Bobcat (male) & $4.1-17.6^{1}$ & 12 & $20.2-25.3$ & $23.2 \pm 1.7$ & 12 & $19.9-23.2$ & $21.6 \pm 1.1$ \\
\hline Bobcat (female) & & 12 & $20.4-23.1$ & $21.8 \pm 0.8$ & 12 & $18.3-22.2$ & $20.3 \pm 1.1$ \\
\hline Coyote (male) & $7.0-20.0^{2}$ & 767 & $19.6-39.1$ & $30.6 \pm 2.1$ & 760 & $17.6-36.4$ & $28.4 \pm 1.8$ \\
\hline Coyote (female) & & 640 & $18.6-38.0$ & $28.9 \pm 2.0$ & 637 & $15.5-35.0$ & $27.0 \pm 1.8$ \\
\hline Mexican wolf (male) & $23.0-41.0^{2}$ & 39 & $33.3-49.8$ & $43.1 \pm 4.0$ & 38 & $27.8-43.7$ & $38.7 \pm 4.6$ \\
\hline Mexican wolf (female) & & 24 & $31.4-45.7$ & $39.1 \pm 3.1$ & 23 & $28.1-39.9$ & $35.0 \pm 3.0$ \\
\hline Mountain lion (male) & $36.0-103.0^{2}$ & 19 & $35.0-48.0$ & $42.2 \pm 3.2$ & 19 & $32.0-44.0$ & $38.8 \pm 2.7$ \\
\hline Mountain lion (female) & & 8 & $32.0-39.0$ & $36.9 \pm 2.2$ & 8 & $31.0-38.0$ & $32.6 \pm 2.3$ \\
\hline
\end{tabular}

function. Kernel densities that are identical result in a value of 1 and those with no overlap result in a value of 0 .

\section{Results}

Lower intercanine width was smaller than upper intercanine width for all species, and patterns in variation and relative width in comparison to other species were very similar (Table 1; Fig. 1). For all species, females had smaller mean upper and lower intercanine widths. The range of spread between males and females was similar for all species. Combining the upper and lower intercanine measurements generally increased the amount of variability in the data and therefore the overlap scores between pairs of species except for the larger carnivore species (Table 2). Smaller carnivores (i.e., foxes and bobcats) had lower overlap scores compared to the larger carnivores (i.e., coyotes, Mexican wolves, and mountain lions), with mountain lions and Mexican wolves having the highest overlap score (Table 2; Fig. 1). Coyotes overlapped the most with feral dogs (0.31), but also showed some overlap (0.16) in the lower range of intercanine width of Mexican wolves and mountain lions (i.e., 28-35 mm). Feral dogs had intercanine widths that overlapped with all the native carnivore species but overlap was highest with Mexican wolves (0.69) and mountain lions (0.76; Table 2; Fig. 1). All native canids except for the gray fox showed some degree of overlap with each other (Fig. 1). For depredation investigations possibly involving Mexican wolves, intercanine width measurements between about 28 and $35 \mathrm{~mm}$ had the most potential to be confounding because these measurements overlapped with the most species (Fig. 1).

\section{Discussion}

Our results indicate that using intercanine width measurements to identify the predator species responsible for a kill should be used cautiously and in conjunction with other forensic evidence such as rake marks, the manner in which the animal was killed, where the puncture wounds occur on the body, and consumption or scatter of the carcass. This is especially pertinent in areas of Mexican wolf recovery when feral dogs are present on the landscape due to the potential similarities in kill sites between the 2 species.

In the current system of classifying depredation events, the difference in hunting styles normally results in a clear distinction between kills by felids and canids (New Mexico Cooperative Extension Service and Range Improvement Task Force 2008). Mountain lions stalk their prey and will usually kill by biting the back of the neck or top of the head, with claw marks along the shoulders. They will often begin feeding at the abdomen, bones will have clean-cut edges, and they will cache the carcass. Canids, however, lunge and bite at the hindquarters, making the kills less clean than those of felids. Carcasses are often disemboweled and strewn across the site, and bones will be broken with ragged edges. However, when investigating kills potentially made by Mexican wolves, extra scrutiny would be required to accurately classify the canid responsible in areas with sympatric wolves, feral dogs, and coyotes due to the similarity in hunting styles. We found the overlap between Mexican wolves and coyotes primarily occurred in intercanine width measurements between 28 and $35 \mathrm{~mm}$. To a large degree, this low overlap score reflects the wide variation in intercanine width measurements in Mexican wolves and the fact that a long tail in the distribution at the lower end was the primary area of overlap. Thus, there is not as much concern for misidentification between Mexican wolves and coyotes except on the extreme ends of the distribution, the lower end for Mexican wolves and the higher end for coyotes.

We found intercanine width measurements of feral dogs overlapped with every species we sampled (Table 2; Fig. 1), with the most overlap occurring in species that cause the most predation issues (i.e., coyotes, Mexican wolves, and mountain lions). Competition between feral dogs and wild carnivores is 


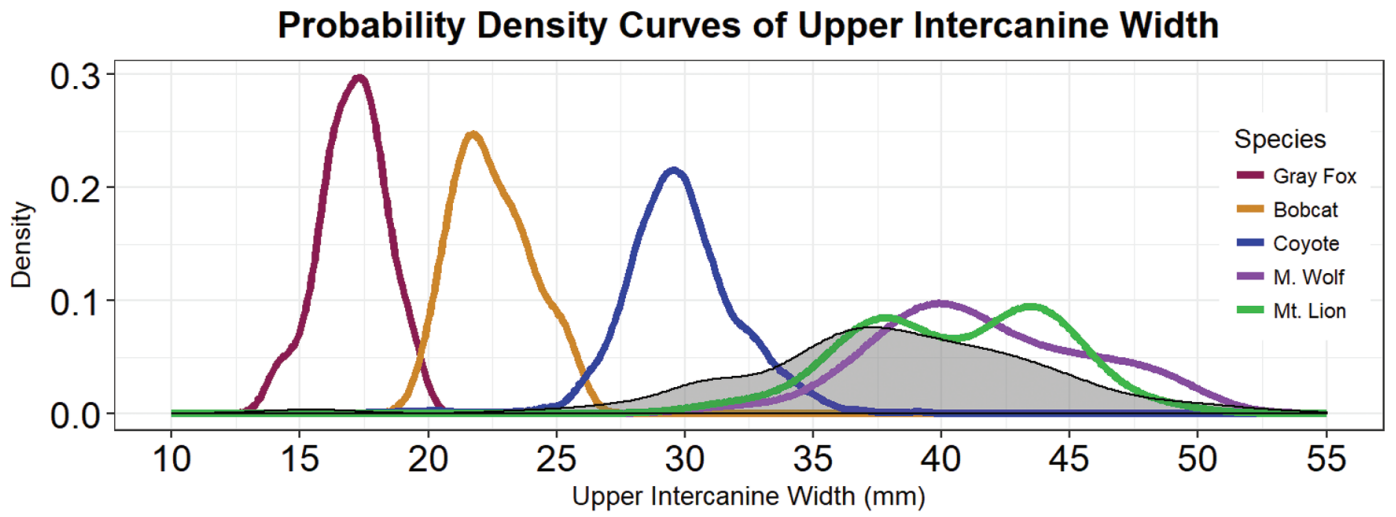

Probability Density Curves of Lower Intercanine Width

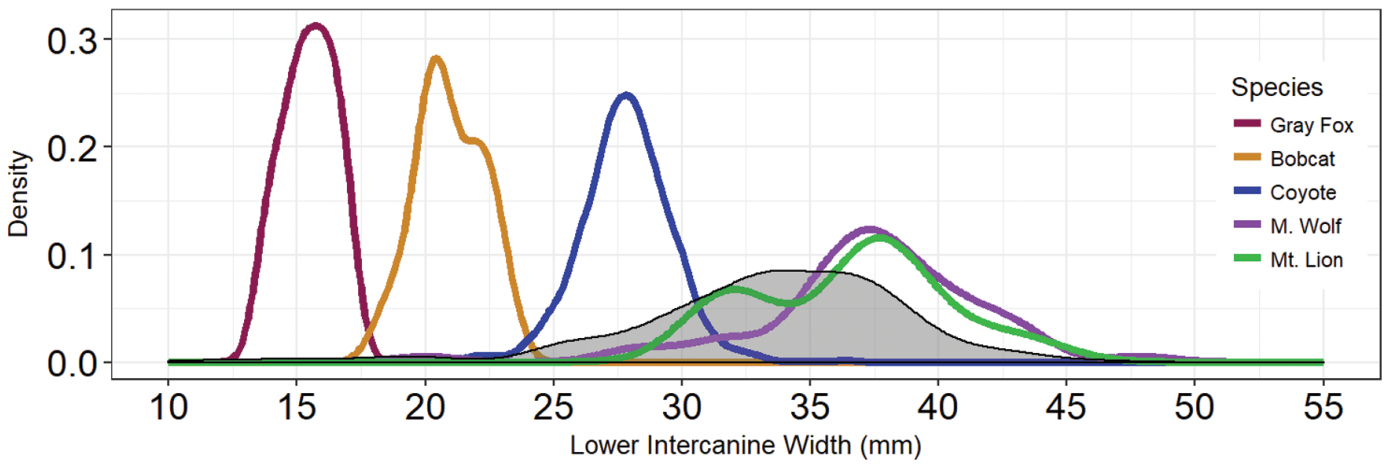

Probability Density Curves of Lower and Upper Intercanine Width Combined

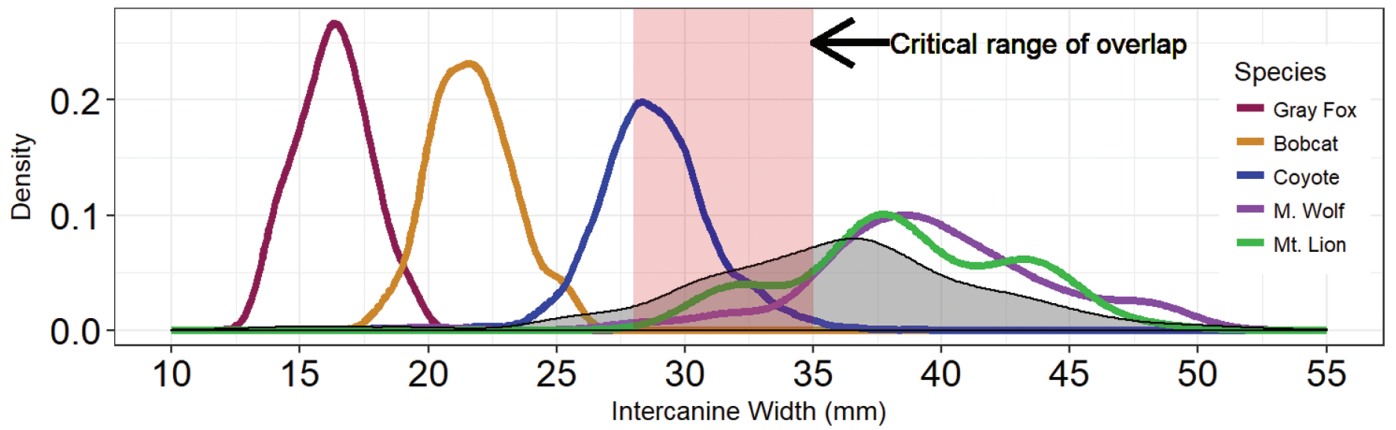

Fig. 1.- Probability density curves of upper, lower, and combined intercanine width measurements for 5 native Arizona predators and feral dogs. The shaded gray area depicts the density curve for feral dogs and the degree of overlap between any 2 density curves is provided in Table 2 .

Table 2.-Overlap coefficients for the following pairs of sympatric carnivore species collected in Arizona, United States, for upper intercanine, lower intercanine, and combined upper and lower intercanine width measurements. We calculated kernel densities for each data set and calculated the overlap coefficient for all pairs of native species whose median values were $10 \mathrm{~mm}$ or less apart and between feral dogs and all native carnivores.

\begin{tabular}{lccc}
\hline Species & Upper canine overlap & Lower canine overlap & Canines combined overlap \\
\hline Gray fox versus bobcat & 0.04 & 0.02 & 0.02 \\
Feral dog versus gray fox & 0.01 & 0.04 & 0.02 \\
Feral dog versus bobcat & 0.02 & 0.27 & 0.05 \\
Feral dog versus coyote & 0.24 & 0.63 & 0.31 \\
Feral dog versus Mexican wolf & 0.71 & 0.74 & 0.69 \\
Feral dog versus mountain lion & 0.78 & 0.11 & 0.76 \\
Coyote versus Mexican wolf & 0.07 & 0.85 & 0.12 \\
Mountain lion versus Mexican wolf & 0.83 & 0.12 & 0.86 \\
Mountain lion versus coyote & 0.10 & \multicolumn{2}{c}{} \\
\hline
\end{tabular}


highest in areas where human-derived food is limited and where feral dogs rely more on wild resources (Vanak and Gompper 2009). Feral dogs will attack livestock and native ungulates (Bergman et al. 2009; Young et al. 2011; Duarte et al. 2016; Wierzbowska et al. 2016). Thus, the high degree of overlap is important because it demonstrates the potential for predation by feral dogs to be confused with that by native predators, especially other canids such as Mexican wolves, and again points to the importance of using additional evidence for classifying kills made by predators.

Some of the wide variation in the measurements of feral dogs that we recorded likely arose from the fact that they were collected following roundups on the Navajo Nation, where there are many different breeds and mixes of dogs covering a wide range of sizes. While these roundups occurred in human-populated rural areas, the location where these feral free-roaming dogs were rounded up experiences a high amount of problems documented with feral and free-roaming dogs preying on livestock and native ungulates. Although I-40 intersects the Navajo Nation and only a small portion of the Nation exists below I-40, feral dogs north of the interstate are likely representative of those south of it. These geographic areas overlap with the range of Mexican wolves in the southwestern United States (U.S. Fish and Wildlife Service 2017). Given the high degree of overlap, this poses a risk for mistaken identity of Mexican wolves in depredation investigations. As other studies have shown, wolves are often implicated in depredation cases where feral dogs were responsible (Echegaray and Vilà 2010; Caniglia et al. 2013; Duarte et al. 2016).

When performing analyses of bite marks, it can be difficult to distinguish rake marks caused by upper versus lower canines; thus, we combined the upper and lower intercanine widths into a single analysis to better understand how that influenced overlap between species and to better capture the high degree of overall variation seen in intercanine widths within species. For the larger species, combining the upper and lower intercanine widths had little impact on overlap scores (Table 1). This was because the upper and lower intercanine width measurements for the large carnivores were more varied and merging them did not increase the overall variation. In contrast, in the smaller carnivore species, variation in upper and lower intercanine width measurements were smaller, creating more-distinct distributions between the upper and lower measurements, that when combined increased the overall variation and therefore expanded the density distribution and overlap scores between species. Our results imply that considering upper versus lower intercanine width is not as important as understanding differences between species because of the difficulty determining upper and lower canine puncture wounds on carcasses.

We found that calculating an overlap coefficient was useful because we could compare similarity between distributions and not just point estimates, and examine the probability of overlap for any given measurement within the range for that species. For example, the range of intercanine width measurements for coyotes and Mexican wolves fall completely within the range for feral dogs (Table 1), but it is difficult to determine from commonly reported descriptive statistics (e.g., mean and standard deviation) the degree to which these species overlap. When we examined the degree to which the density plots overlap (Fig. 1), it is clearer that a larger number of feral dogs have upper and lower intercanine widths that are more similar to Mexican wolves than to coyotes. This type of information can provide important insight into critical measurements where greater caution is required, especially with species such as Mexican wolves, where public perception is key to maintaining the success of the ongoing reintroduction.

When comparing our data to other studies, we found that in general, the intercanine width measurements we reported were similar, with some being slightly smaller, to those reported by other studies (Murman et al. 2006; Foust 2010). All of the specimens measured in Murman et al. (2006) and Foust (2010) were obtained from museums and consisted of carnivores from around the United States, Mexico, and Canada. Only 2 of the 53 wolves and 12 of the 54 coyotes sampled by Murman et al. (2006) were from a geographic region similar to that of our study. Thus, the slight differences between studies are likely due to geographical differences in the size of carnivores, with smaller individuals occurring in the southwestern United States compared to other geographical areas.

Public perception is important in controversial species reintroduction efforts (Kellert et al. 1996). Therefore, it is important to identify the correct culprit in depredation investigations. We showed that there is a high degree of overlap in intercanine width measurements between sympatric carnivores, especially between Mexican wolves and feral dogs. Therefore, dentition measurements alone would not likely be definitive enough to provide a clear picture of which predator was responsible for killing domestic livestock or native ungulates. However, when investigators possess knowledge on the ranges of measurements that can be most problematic in regards to fitting multiple species' profiles, extra caution can be employed. When coupled with information gathered at the kill site, these measurements can help investigators and managers make informed and accurate conclusions about the predation event.

\section{ACKNOWLEDGMENTS}

We thank all of the Wildlife Services Arizona field program personnel for collecting the data and the Mexican Wolf Species Survival Plan members for providing data. We also thank the Navajo Nation Fish and Wildlife Department for assisting with the data collection through their Animal Control program and staff. The findings and conclusions in this article are those of the author(s) and do not necessarily represent the views of the U.S. Fish and Wildlife Service.

\section{Literature Cited}

Acorn, R. C., And M. J. Dorrance. 1990. Methods of investigating predation of livestock. Alberta Agriculture and Rural Development, Edmonton, Alberta, Canada. Publication number AGDEX 684-14. Amirkhiz, R. G., J. K. Frey, J. W. Cain III, S. W. Breck, and D. L. Bergman. 2018. Predicting spatial factors associated with cattle depredations by the Mexican wolf (Canis lupus baileyi) with 
recommendations for depredation risk modeling. Biological Conservation 224:327-335.

Arizona Game and Fish Livestock Board. https://www.azgfd.com/ agency/livestockboard/committe/. Accessed 28 July 2017.

Bergman, D. L., S. C. Bender, and S. W. Breck. 2010. Depredation investigation: using canine spread to identify the predator species. Pp. 304-307 in Proceedings of the 24th Vertebrate Pest Conference, Sacremento, California, 22-25 February 2010 (R. M. Timm and K. A. Fagerstone, eds.). University of California, Davis.

Bergman, D. L., S. W. Breck, and S. C. Bender. 2009. Dogs gone wild: feral dog damage in the United States. Proceedings of the Wildlife Damage Management Conference 13:177-183.

Blejwas, K. M., C. L. Williams, G. T. Shin, D. R. McCullough, and M. M. JAEGER. 2006. Salivary DNA evidence convicts breeding male coyotes of killing sheep. The Journal of Wildlife Management 70:1087-1093.

BRECK, S. W., ET AL. 2011. Factors affecting predation on calves and producer detection rates in the Mexican wolf recovery area. Biological Conservation 144:930-936.

Caniglia, R., E. Fabbri, L. Mastrogiuseppe, and E. Randi. 2013. Who is who? Identification of livestock predators using forensic genetic approaches. Forensic Science International Genetics 7:397-404.

CiUcCI, P., AND L. Boitani. 1998. Wolf and dog depredation on livestock in central Italy. Wildlife Society Bulletin 26:504-514.

Clucas, J. L. 2005. A field guide to predatory animal damage identification. Hawk Haven Media, Shell, Wyoming.

DuARTE, J., F. J. GARCIA, AND J. E. FA. 2016. Depredatory impact of freeroaming domestic dogs on Mediterranean deer in southern Spain: implications for human-wolf conflict. Folia Zoologica 65:135-141.

ECHEGARAY, J., AND C. VILÀ. 2010. Noninvasive monitoring of wolves at the edge of their distribution and the cost of their conservation. Animal Conservation 13:157-161.

Feldhamer, G. A., B. C. Thompson, AND J. A. Chapman (eds.). 2003. Wild mammals of North America: biology, management, and conservation. The Johns Hopkins University Press, Baltimore, Maryland.

Foust, J. L. 2010. The use of tooth pit and tooth/jaw measurements to identify carnivore taxa responsible for damage on scavenged bone. M.A. thesis, University of Montana, Missoula.

Kellert, S. R., M. Black, C. R. Rush, and A. J. Bath. 1996. Human culture and large carnivore conservation in North America. Conservation Biology 10:977-990.

Lyver, P. O. B. 2000. Identifying mammalian predators from bite marks: a tool for focusing wildlife protection. Mammal Review 30:31-44.

Mumma, M. A., C. E. Soulliere, S. P. Mahoney, and L. P. Waits. 2013. Enhanced understanding of predator-prey relationships using molecular methods to identify predator species, individual and sex. Molecular Ecology Resources 14:100-108.

Murman, D. C., P. C. Brumit, B. A. Schrader, and D. R. Senn. 2006. A comparison of animal jaws and bite mark patterns. Journal of Forensic Sciences 51:846-860.
New Mexico Cooperative Extension Service and Range Improvement TASK ForCE. 2008. A guide to identifying livestock depredation, Report 77. http://aces.nmsu.edu/pubs/_ritf/RITF77.pdf. Accessed 14 October 2015.

NowaK, R. M. 2005. Walker's mammals of the world. 6th ed. The Johns Hopkins University Press, Baltimore, Maryland.

Onorato, D., C. White, P. Zager, And L. P. Waits. 2006. Detection of predator presence at elk mortality sites using mtDNA analysis of hair and scat samples. Wildlife Society Bulletin 34:815-820.

R Core Team. 2015. R: a language and environment for statistical computing. R Foundation for Statistical Computing. https:// www.R-project.org/. Accessed 29 June 2018.

Ridout, M. S., AND M. Linkie. 2009. Estimating overlap of daily activity patterns from camera trap data. Journal of Agricultural, Biological, and Environmental Statistics 14:322-337.

U.S. Fish and Wildlife Service. 2009. Mexican Wolf Husbandry Manual. https://www.fws.gov/southwest/es/mexicanwolf/pdf/ Mexican_Wolf_Husbandry_Manual_2009.pdf. Accessed 15 May 2017.

U.S. Fish and Wildlife Service. 2017. Mexican Wolf Recovery Program: Progress Report \#19. https://www.fws.gov/southwest/ es/mexicanwolf/pdf/2016MexicanWolfProgressReportFinal.pdf. Accessed 10 September 2018.

U.S. Fish and Wildlife Service, Mexican Wolf Depredation Compensation. 2016. https://www.fws.gov/southwest/es/mexicanwolf/pdf/Coexistence_Council_Compensation_Guidelines.pdf. Accessed 15 May 2017.

U.S. Fish And Wildlife Service Press Release. 2018. 2016 Mexican wolf population survey reveal gains for experimental population. https://www.fws.gov/news/ShowNews. cfm?ref=2016-mexican-wolf-population-survey-reveal-gainsfor-experimental-\&_ID=35981. Accessed 16 March 2018.

VAnaK, A. T., AND M. E. GompPer. 2009. Dogs Canis familiaris as carnivores: their role and function in intraguild competition. Mammal Review 39:265-283.

Wierzbowska, I. A., M. Hedrak, B. Popczyk, H. Okarma, and K. R. Crooks. 2016. Predation of wildlife by free-ranging domestic dogs in Polish hunting grounds and potential competition with the grey wolf. Biological Conservation 201:1-9.

Young, J. K., K. A. Olson, R. P. Reading, S. Amgalanbatar, and J. BERGER. 2011. Is wildlife going to the dogs? Impacts of feral and free-roaming dogs on wildlife populations. BioScience 61:125-132.

Young, A., R. Stillman, M. J. Smith, and A. H. Konstjens. 2015. Scavenger species-typical alteration to bone: using bite mark dimensions to identify scavengers. Journal of Forensic Sciences 60:1426-1435.

Submitted 17 January 2018. Accepted 22 October 2018.

Associate Editor was Bradley Swanson. 